Benchmark

\title{
Strategic Thinking for Sustainability: A Review of 10 Strategies for Sustainable Mobility by Bus for Cities
}

\author{
Gonzalo Fernandez-Sanchez * and Alvaro Fernandez-Heredia \\ EMT de Madrid, 28007 Madrid, Spain; alvaro.fernandez@emtmadrid.es \\ * Correspondence: gonzalo.fernandez@emtmadrid.es
}

Received: 8 September 2018; Accepted: 15 November 2018; Published: 19 November 2018

\begin{abstract}
The sustainable mobility of the future comes about through sustainable ways of transport, such as walking, cycling, or collective transport. This includes the bus, the underground, and trains in big cities. This article reviews bus-related policies and initiatives worldwide. It also analyses ten cities looking at medium and long-term strategies for the urban bus service. The main ideas are: the forecasts for the use of the urban bus system indicate a significant increase in demand, therefore, there is a need for expanding the offered services; efforts to change the fleets towards Compressed Natural Gas and Electric vehicles; support of technological innovation for communication and accessibility; improving commercial speed and frequencies by infrastructure improvements, operation optimisation and technology; and, the link between these strategies and the air quality of cities. The transition towards a sustainable transport will happen based on the belief that the bus service is no longer the transport of the past or the present, but of the future.
\end{abstract}

Keywords: strategic thinking for sustainability; strategic thinking approaches; transitions to sustainability; sustainable mobility; transport strategy; transport plan

\section{Introduction}

At a time when sustainable mobility is a topic in any forum about sustainability, transport, and urban planning; attention to public transport becomes necessary. Public transport is essential to achieve the objectives of air quality, healthy cities, traffic decongestion and accessibility for those who are disadvantaged in terms of mobility [1]. In this sense, transport by foot, bicycle, or bus (also by underground or train in the case of big cities) are key to achieving these objectives. Thus, authors such as Silvia Cruz and Katz-Gerro [2] have focused on the study of public transport companies as essential entities for the development of sustainability in their production chain; and how public policies, economic resources, and the oil market restrict the possible strategies towards improving the environment.

In this context, the bus transport service as public urban transport is essential. Following UITP (International Association of Public Transport) some $80 \%$ of all public transportation passengers worldwide are by buses [3]. Despite different developments in the bus system, there is not a clear consensus on the most effective means to improve bus services [4]. Analysing its status, the society's participation in the system, as well as its strategies in the short and medium term can be very relevant to understand trends in this sector. Therefore, there are theoretical studies that are focused on improving the planning and timetable control of the bus transport system, e.g., [5]. In addition, those like Diab et al. [6] that propose strategies to improve the bus system by integrating stakeholders, which are mainly passengers. These studies also include the improvement of infrastructure, accessibility, and equity focus on low-income groups, as well as improving investment in time and money with 
Bus Rapid Transyt (BRT) systems [7]. However, there are no analyses of the integrated and holistic strategies that companies and cities are proposing in relation to the urban bus transport system, neither in the short, medium, nor long term. There is no link between upper and lower levels of urban mobility systems, so in most of the decisions of cities worldwide, the operational and strategic levels are confused and clearly lack a defined strategy [8].

There are specific studies of two cities in this sense [9], theoretical studies of the overall improvement of the efficiency and effectiveness of urban public transport in general [10] and several studies analysing measures to improve the bus system [11-13]. The relation between urbanism, mobility, and air quality and pollution by emissions has also been analysed, and the connection of these elements with the improvement of speed, frequency, and the network to reduce these emissions [14].

It is at this point that we want to reflect on the bus transport system as a key element for a sustainability strategy (urbanism, mobility, and air quality) in any city of the world from the perspective of the strategies of different cities, cultures, and operators of the world by analysing their perceptions as experts and planners of the future urban bus service.

However, following most studies, one might get the feeling that sustainable mobility of the future is going in other directions that are more focused on more innovative ways of transport: Connected and Autonomous Vehicles (CAVs), Flying vehicles, Shared Used Mobility (SUM), Hyperloop technology, and Mobility as a Service (MaaS). Some authors have treated these innovations as the mobility of the future in the case of flying vehicles and transportation $[15,16]$ or the application of Hyperloop technology for the transport of future generations $[17,18]$ as an entirely new disruptive mode with an estimated speed $>1000 \mathrm{~km} / \mathrm{h}$ [19].

SUM as well as car sharing can help establishing a culture for using mobility on an as-needed base $[20,21]$. CAVs are still under development with different prototypes around the world and some ethical dilemmas to solve that will change the urban landscape [22-24]. A step further is the application of technology for planning mobility packages that could entirely replace private modes in urban city centre movements [25]. There are some initiatives in Finland, Germany, and Spain, but they are too new, benefits exist only theoretically and when looking for a transparent cooperation the unification of transport modes is a big challenge.

The question is: Will some of these innovations be the sustainable collective urban transport system of the future? An attempt will be made to find an answer to this question through a tour of the urban transport strategies, focusing on the effects that these sustainable strategic concepts have on the urban bus service and the role they play in the city on a global level.

\section{Objectives and Scope}

The main objective of this article is to analyse the goals and strategic plans of ten cities focused on urban collective bus transportation at a global level. Firstly bus-related policies and initiatives reviews are developed in order to state a brief context, but also to allow for a structured comparison between different cities and approaches.

Ten cities were selected following similar criteria as other authors [24]. In this sense, the city must have a good level of infrastructure and must to be big in terms of population size, since in an initial approach the scope is focused on big cities. The following cities have been chosen (Figure 1): New York, Memphis, Oman, Montreal, Santiago de Chile, Bogota, Melbourne, London, Singapore, and Madrid. The availability of information from the city and, where applicable, the transport authority and/or the bus company responsible for the service in the city was also an essential for the selection. 


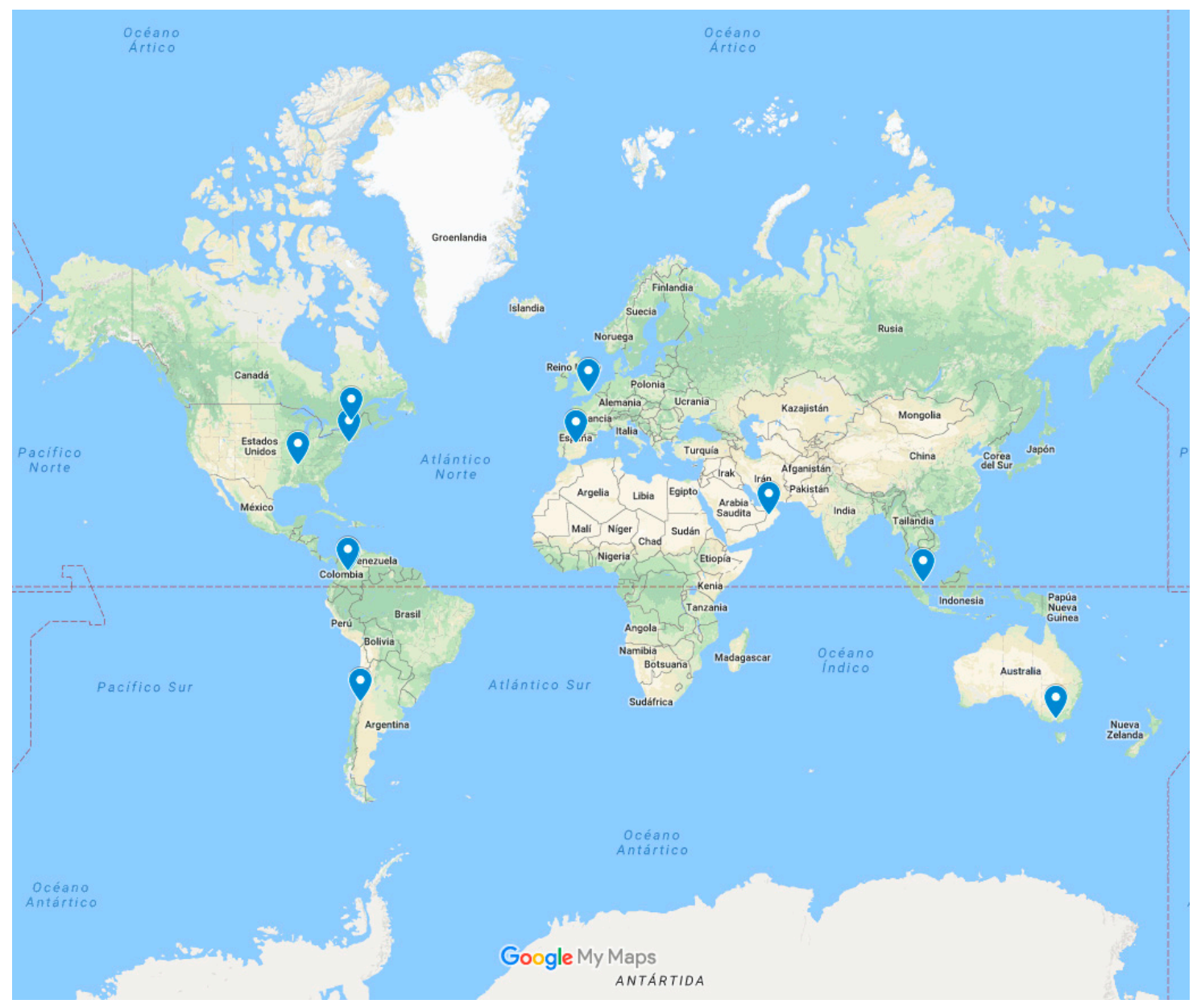

Figure 1. Analysed cities in this study (based on Google Maps).

The study focuses on analysing the main used proposals and methodologies to carry out the plan, as well as analysing the time period and international trends in collective transport mobility. This study was done during 2017.

The study method of each case has been a detailed review of the plans and discursive saturation analysing the design method of the plan, the objectives and the vision of the strategy of each city in the short, medium, and long term.

\subsection{Bus-Related Policies and Initiatives-State of Knowledge}

Following Currie and Rose [1] a framework for public transportation can be drawn to focus on main characteristics. In this sense, Figure 2 shows the barriers (around the framework) and internal (inside the framework) and external factors that affect public transport.

A solution for moving large numbers of people at a relatively fast speed in densely populated areas is the BRT, Bus Rapid Transit [26]. It tries to get most of the items from Figure 2: frequency, speed, on-time performance, reliability, travel time advantages, integration of Intelligence Transport Systems (ITS) technologies, like real-time passenger information or electronic payment and short waiting time. More than 186 cities are actually using BRT systems [12].

The adaptation of the American BRT concept to the European urban context emerged in France in the 2000s called BHLS, Bus with High Level of Service [3]. Bot concepts and bus corridors have been adopted worldwide because of its relative rapid implementation for improving transit services [11]. It is not limited to small and medium sized cities, since it is applied in Mexico DF, Rio de Janeiro, Beijing, New York, while being more common in emerging countries. Technologies, which are 
applied to new improvements in BRT and bus systems in general, are those based on: running way guidance; propulsion technologies; improving reliability; ICTs (off-board payments, electronic tickets); bus priority measures; User Information Systems UIS to increase the passenger experience off-board (app, stations, stops) and on-board (travel experience); adjusted routes and advanced software for scheduling operations where most of the costs are hatndled [27]. Separated bus lanes seem to be effective enough in urban areas, as practical and empirical experience shows [13], where operating speed in a separated bus line in a city centre is comparable to the speed of buses operating along volume corridors.

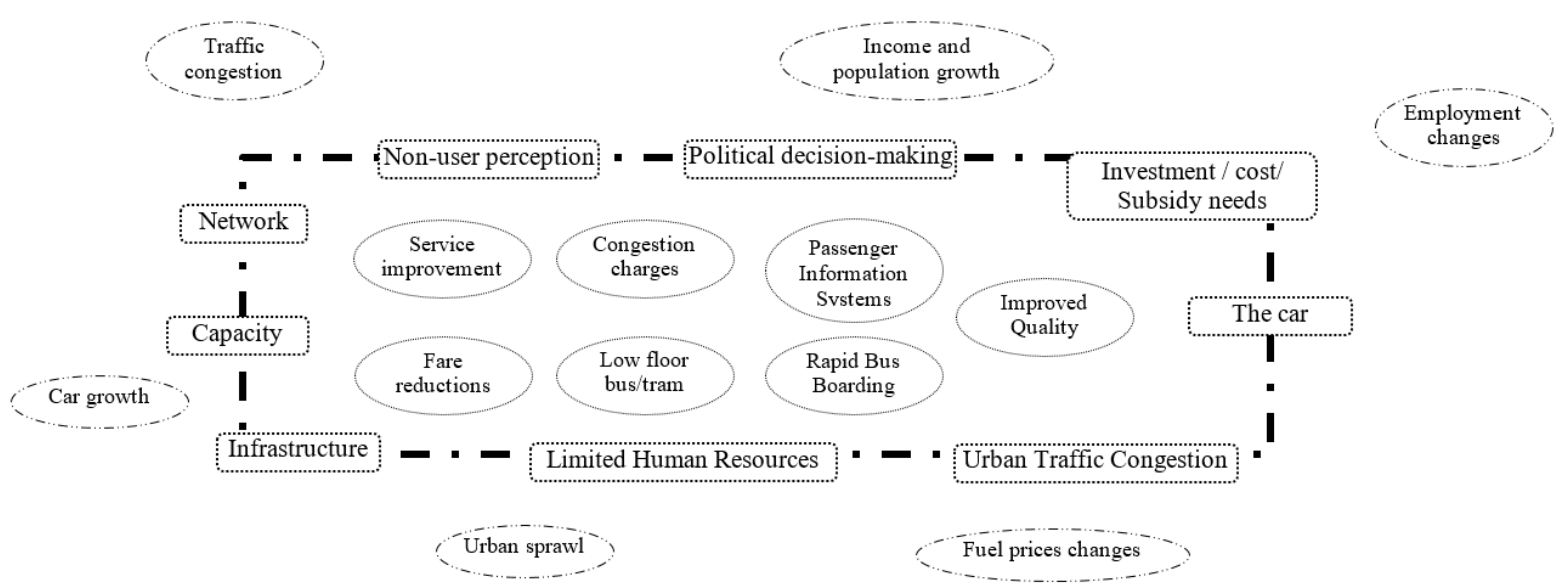

Figure 2. Barriers, internal and external factors (based on Currie and Rose [1]).

There is an importance of climate change and Green HouseGas emissions from transportation. Therefore there are some models that integrate urban transport, land use, and environmental strategies in order to assess during years changes, taking into account fuel efficiency, traffic congestion, carbon taxes, and improvements in public transportation [8,21]. They conclude that a mix of measures for public transportation is the best option when thinking on the environment. Electrical buses deliver zero emissions while operating (but they need more time to recharge what can affect the number of buses to be acquired, which are also more expensive). Effectiveness of cleaner bus fleets has been acknowledged worldwide [28] as can be seen by the C40 network of big cities, where in the recent clean bus declaration 22 signatory cities committed to convert $25 \%$ of vehicles into cleaner ones [29].

A great effort is being done to get more sustainability in local bus transport systems as can be seen in international research projects in the field: EBSF (European Bus System of the Future)-2008-2013 and its continuation EBSF_2 2015-2018, 3iBS (the Intelligent, Innovative Integrated Bus System) 2012-2015; ZeEUS (Zero Emission Bus Systems) 2013-2016; ELIPTIC (ElectrIfication of Public Transport in Cities) 2015-2018; and ECCENTRIC (innovative solutions for sustainable mobility and emission free freight in urban centres) 2016-2020. There is a common objective to all these projects: to develop innovative solutions, to increase attractiveness, and to operate more environmentally friendly.

Even though diesel is still the most used fuel, and electric vehicles are too new for having a complete fleet based on them, some different cleaner fuels without particulate matter are being used. For example, Compressed Natural Gas (CNG), while still being hydrocarbons, drastically reduces NOx local emissions [11].

Technology applied to urban planning and public transportation by introducing smart technology is what is known as smart cities [30]. There are many initiatives promoting smartness in urban transport systems but not much is known about how these systems are performing.

As a conclusion of this brief review, there are some measures for improving the bus system in urban environments. The following Table 1 summarizes the most important measures that were identified in the reviewed literature. Factors identified as most important for some authors [4] are those related to increasing the service to new areas (reaching bigger spatial coverages) and frequencies 
(improving bus offer), and in second order improving reliability and fare-based measures of bus systems. Depending on city size, the strategy to be implemented may differ, taking into account that the infrastructure cost of a busway is more cost-effective than the one of other modes. If the initial reliability of the bus system is low, an improvement can reach a 10-20\% increase in demand in the short term. BRT systems could be used, as shown, as a best practice to be applied because of the foreseeable increase in frequency, reliability, and priority systems that are linked to the bus system. Cascajo and Monzon [3] analysed measures implemented in bus systems in five European cities to improve its use. Their results were that the most important issues would be to improve comfort, space and security for passengers; to increase efficiency in terms of operational costs while meeting environmental targets; to improve internal bus lay outs for a better flow of passengers reducing dwell time and increasing commercial speed; to reach a greater perception by both, users and non-users; and, ITS measures to make bus systems more attractive and reach reliability on waiting time ranges.

Table 1. Measures for urban bus system improvement.

\begin{tabular}{|c|c|}
\hline Areas & Measures for Improvement \\
\hline Infrastructure and Operations & $\begin{array}{l}\text { BRT/BHLS } \\
\text { Separated Bus Lanes } \\
\text { Restructuration and optimization of lines } \\
\text { Modifying the offer } \\
\text { Express and limited stop bus services } \\
\text { More frequency } \\
\text { Bus priority measures } \\
\text { Advanced software for operation management } \\
\text { Adequation of facilities and depots } \\
\text { Human resources (training, sensitivity) } \\
\text { Networks connections }\end{array}$ \\
\hline Bus Service Quality—Attractiveness & $\begin{array}{l}\text { Bus marketing } \\
\text { Passenger information measures (RTI, Real Time Information) } \\
\text { Frequency/Regularity } \\
\text { Fares } \\
\text { Reliability } \\
\text { Availability of information for connecting to other public transportation } \\
\text { services (MaaS) } \\
\text { Easy boarding/Comfort } \\
\text { Non-user perception } \\
\text { Customer experience }\end{array}$ \\
\hline Vehicles (Buses) & $\begin{array}{l}\text { Major new buses (CNG, electrical vehicles, hydrogen) } \\
\text { Mini buses } \\
\text { Accessibility for all users } \\
\text { Adapted Vehicles } \\
\text { Hybrid (electric based) } \\
\text { Safety and security } \\
\text { Technical and economical maintenance } \\
\text { Passenger accounting systems }\end{array}$ \\
\hline
\end{tabular}

\subsection{New York (USA): MTA Capital Program 2015-2019}

The Metropolitan Transportation Authority (MTA) is the largest transportation network in North America, serving a population of 15.3 million people in an area that runs from New York to Long Island and from southeast New York to Connecticut. The MTA operates both, the bus system and the New York subway network.

The Strategic Plan of the MTA Capital Program 2015-2019 presents an ambitious expansion program with a budget of more than 32 billion dollars.

The MTA Bus Company was created in 2004 with the merger of seven private companies, which was subject to concessions with the city of New York. 
To elaborate the strategic plan the MTA has worked with labour unions, and in parallel collaborated with the New York City authorities. The three basic lines of action that affect the bus service are:

Renovation: to improve the security, reliability, and quality of the existing service. It involves the renovation of the bus fleet and vehicle depots. It also includes the introduction of contactless technology, modernizing, and improving the efficiency of the service.

Improvement: the accessibility of public transport systems to people with reduced mobility and the implementation of transit schedule information systems.

Expansion: incorporating new routes in collaboration with the New York City Department of Transportation (NYCDOT).

The MTA will acquire more than 1700 low-emission diesel, hybrid-electric, and compressed natural gas buses. The new buses are more energy efficient and less polluting than the previous ones. The current average age of the fleet is 13 years.

In addition, all of the buses in the fleet will be equipped with passenger accounting systems.

The strategic plan of the MTA includes priority repairs of bus depots such as the reconstruction, modernization and expansion of the depots in Jamaica, where more than $\$ 298$ million will be allocated.

Additionally, more than $\$ 250 \mathrm{M}$ will be designated to maintenance facilities, washing tunnels, fuel tanks, or electric sub-stations for the eight bases it has.

The Select Bus Service (SBS) network provides a complementary service to the subway system, connecting neighbourhoods to subway stations called Bus Rapid Transit (BRT). To improve the reliability and service along these corridors with a high number of passengers, a series of measures will be implemented. These include the payment of fees outside the vehicle, reserved platform lanes, traffic signal priority, and more space between stops. In the Strategic Plan of the MTA, the expansion of Select Bus Service has the aim of improving the efficiency of the system and increasing the number of passengers by acquiring 345 new buses.

\subsection{Memphis (USA): Livability 2040}

The Livability 2040 Regional Transportation Plan (RTP) is the strategic plan that was developed by the Metropolitan Planning Organization of Memphis (MPO), which will guide the spending of federal transportation funds for all means of transportation over the next 25 years. The RTP is made up of local, state, and federal policy makers and by citizens, business owners, and by those stakeholders who are most affected by transportation decisions. The plan establishes the purpose and need for big investments in transportation, identifies activities to address the main transportation problems, and prioritizes investments to improve the condition of the system.

The time frame of the RTP Plan is a minimum of 20 years; it is subject to fiscal restrictions for all financed projects and is specifically concentrating on air quality.

For the realization of the Strategic Plan 2040 RTP, special importance was given to the opinion of the citizens of Memphis and the stakeholders. For this, a wide dissemination and bi-directional communication was carried out, and the data that was gathered was applied to the development of objectives for the region and the identification of transportation needs. Numerous techniques and tools were used, for example: videos showing several mayors in debates about the strategic plan, press releases, radio interviews, public meetings, stakeholder meetings, postcards, school visits, bus announcements, mass emailing, newsletters, surveys, on-line suggestion maps, social media, etc.

The main points of the 2040 RTP strategic plan that affect the bus network are the following:

Improvements in bus installations: including construction and repair of maintenance, operation, and passenger exchange facilities.

Acquisition of new rolling stock: this project provides funding for the purchase of up to 120 buses between the fiscal years of 2016 and 2019. Up to 120 diesel buses, which have completed their 
lifecycle, will be replaced. These buses generally have a life cycle of 12 years or 500,000 miles. Buses will be renewed according to the FTA's current policy of rolling stock.

Improvement of preventive maintenance: providing funds for materials and supply; inspections and routine maintenance needed to maximize the efficiency of the life cycle, including bus fleets, fix routes, and supply for the demand.

New bus lanes and Bus Rapid Transit (BRT): The idea is to boost the public transport in the city of Memphis. Therefore, the action line of the strategic plan is the creation of new routes and the reinforcement of existing ones.

\subsection{Montreal (Canada): Strategic Plan 2020}

The Société de Transport de Montréal (STM) employs more than 9000 employees and operates more than 1.2 million trips a day, managing a budget of 1150 Canadian Dollars.

The STM has a fleet of 1680 buses, of which eight are hybrids and 140 are articulated. The bus service covers practically the total island of Montreal equalling $500 \mathrm{~km}^{2}$. The service is composed of 209 bus lines: 156 are wheelchair accessible and 23 are dedicated to night services. Moreover, the bus system has $101.4 \mathrm{~km}$ of reserved bus lanes.

The focus is on an optimized customer experience in terms of frequency, speed, punctuality, and comfort. It is supported by big expenditure in maintenance equipment and strategic expenses, which are linked to a more than $30 \%$ growth up to 2025 . STM will only buy $100 \%$ electric vehicles.

The strategy of Montreal and the government of Quebec is aimed at reducing the only one car per person use, which implies that it will increase the number of passengers by $40 \%$, getting up to 540 million trips in 2020.

The pillars of Montreal's strategic plan are:

Making public transport the most implemented mode of transport.

Reducing Greenhouse Gases.

Being the first place in North America where public transport is $100 \%$ electric.

Boosting the economy through the public transport in Quebec.

Therefore, the following priorities are established: expanding services, improving the customer experience, attracting and retaining talent, optimizing management, and sustainable development at the heart of all decisions.

\subsection{Santiago de Chile (Chile): Master Plan 2025}

The Master Plan of Santiago de Chile 2025 was born due to the need for a guideline for the management and strategic investment in infrastructures. This defines an urban transport system focused on the mobility needs of the people and goods in Santiago. In addition, the plan includes the need to improve the existing congestion, which has become a lot worse in recent years.

Following the motorization growth trend in Santiago, the number of vehicles will double between 2012 and 2025 (from 1.3 to 2.7 million).

The Transport Master Plan Santiago 2025 aims at generating a coordinated program of projects, which includes different methods and institutions that satisfy the following objectives: efficiency, mass transport, equity, sustainability, and safety. Together with the aforementioned objectives, there were several directives that lead the development of the master plan and represent the spirit in which it was developed.

In the methodology that was used in this strategic plan, first a diagnosis of the current and future mobility conditions in the city was carried out. City development trends were investigated, generating a simulation of Santiago for the year 2025 in terms of population localization and economic activity. Using this data base, it was possible to estimate the future motorization rate and to project the generated trips for different areas of Santiago. 


\subsection{Bogota (Colombia): Strategic Transport Plan}

TransMilenio or Empresa de Transporte del Tercer Milenio S. A. is a BRT-like transport system that is part of the mass transport system of Bogota and Soacha (Colombia). Its construction began in 1998 and it was inaugurated on the 4th of December 2000. The system is composed of the main lines and the feeding lines to supply the core lines. It is part of the SITP (Integral Public Transport System), used in tandem with complementary and special urban services that run through the main neighbourhoods and roads of the city.

According to the incumbent plans of the mass transport system of Bogota, TransMilenio will finish its construction by 2031 with a total of eight phases, $388 \mathrm{~km}$ of core lines, covering $80 \%$ of public transport trips in the city. The main strategies are: improving the operation system with quality and comfort standards; improving user safety and reducing accidents; widening the coverage of the integrated public transport system; articulating and developing a technological improvement plan; generating an environment protection culture; developing and strengthening user communication channels; designing and implementing a corporate social responsibility strategy; ensuring the financial balance of the system; and, obtaining income by the commercial implementation of different components of the system.

\subsection{London (United Kingdom): Strategic Transport Plan}

Transport is a fundamental activity in London and therefore the core of many present and future challenges for the city. The main objective of the Mayor's Transport Strategy is to create a future London that is not only the home for more people, but a better place for all of these residents. Based on the reduction of the Londoner's car dependence, favouring walking, bicycle, and public transport permanently changing the distribution mode of transport is the future success for London.

The objective to reduce private vehicles will help to solve many of London's health problems, by reducing the inhabitants' inactivity and the cleaning of the air. It will limit the city's contribution to climate change and will help to develop local environments.

The objective of the strategic plan for 2041 is that $80 \%$ of Londoners will travel by foot, cycling, or by using public transport.

There are two fundamental elements in the bus service strategy in London:

Planning the bus network-Curiously, the bus network has been developed in the last few decades to adapt to changing travel demands, the transport network, and the passengers. The circumstances change constantly and a bigger service development is needed to adapt to these recent changes. In the strategic plan, it is suggested to plan new bus routes to connect new boroughs and support the real estate and employment growth. This flexibility also makes buses the perfect means to offer public transport options to areas of London that are changing. It is essential, that the TfL (Transport for London) buses satisfy the demand of Londoners and visitors and reach their potential to support the future transport of London. It will be important to take maximum advantage of the bus network's flexibility, to reduce and eliminate existing services when they are no longer needed in the centre of London, and to use this freed capacity to give new and better service in the outskirts of London. This can happen in areas with significant real estate growth or where the transport connection is not adequate. This will play an important role in achieving the strategy's objective to reduce the harmful effects of the car.

Improving bus travelling time and reliability. Focussing on healthy roads in inner and outer London will require a significant increase of trips made by bus instead of by car. Reliable and reasonable bus travelling times through London are essential to make the bus service appealing to existing and potential customers. With adequate resources the contracts are incentives to guarantee reliable trips and the support infrastructure (e.g., bus priority, stops, and counters) is protected and has improved. The priority of the buses is essential, including $24 \mathrm{~h}$ bus lanes and corridors for buses and cyclists. Many main ring roads in inner London are bus routes to the 
centre of London. They transport a large amount of people and it is essential that they keep doing this reliably. The measures to improve the reliability of buses on these routes include timetable revision, bus lane construction, traffic light priority, surveillance and performance, behaviour change initiatives, and priority measures. To improve air quality, new low-emission buses will be acquired.

\subsection{Madrid (Spain): Strategic Plan CERCA 2017-2020}

EMT is the Empresa Municipal de Transportes focused on the urban bus service in the city of Madrid with about 2000 buses, more than 200 lines and more than 400 million passengers a year. The strategic plan 2017-2020 of the EMT of Madrid defines the actions to be carried out in the company in the next few years to offer a holistic mobility service in the city to the citizens, improving its quality and committing itself to the air quality in Madrid.

This plan has been innovative in its creation, as it counted on the participation and opinion of the employees, users, and rest of stakeholders, thereby aligning the objectives of all of them by a one year work using workshops, surveys and interviews.

The main objectives of this strategic plan are:

$\square$ Developing participative communication channels as management strategy. Creating traceable bidirectional (physical and technological) communication channels that give a vertical and horizontal connection within EMT, as well as with the stakeholders, mainly users.

Applying innovation and technology to improve the services. Incorporation projects of ecological vehicles (more than 40 electric and more than $900 \mathrm{CNG}$ ), projects to improve the infrastructure (new 100\% electric depot) and operation improvements like the citizen service.

$\square \quad$ Enhancing the pride of belonging to the EMT. This objective seeks to put the employees and users in the centre through a diagnosis of the internal organization and reorganization proposals to improve the efficiency and effectiveness of the organization.

Having a sustainable economic and financial model, focused on investments in technological innovation.

Adapting the organization to be oriented to a service of society taking into account users' and non-users' perception.

Offering a service with the highest quality standards by adapting buildings, fleet, equipment, and facilities to the service.

Maintaining and growing the number of users of the bus system to consolidate the leading position as urban bus operator in Spain and Europe.

$\square \quad$ Exporting the image and knowledge transfer of EMT based on technology-based mobility (e.g., MaaS).

\subsection{Oman: Strategic Plan Mwasalat}

Mwasalat is the main public transport company in the Sultanate of Oman. The main objective of the foundation is to provide a public transport service in the whole Sultanate of Oman. Mwasalat transported more than $1.2 \mathrm{M}$ passengers in 2016.

The strategic plan establishes three time periods: short-term (2016-2018); mid-term (2019-2025); and, long-term (2026-2040). An efficient and sustainable modern urban and intercity transport system is proposed. It includes all modes of transport, which drive the country's social, economic, and touristic development. As a consequence, Mwasalat, the public transport operator, brought the ONTC (Oman National Transport Company) and Ineco together to create the strategic bus transport plan.

The plan uses an already established broad action program to set up a public transport net, the implementation of new urban transport services, and the extension of the already existing current intercity transport net. Moreover, it includes an infrastructure investment program (bus stations, garages, parking areas, etc.), the implementation of new management and exploitation technologies, 
and the definition of financial plans. It also has a progressive implementation of a network of new routes and the construction of reserved platforms (bus lanes).

In parallel, the implementation of new routes and the renovation of the bus fleet have been started. The first 40 urban buses of the new fleet have been running since November 2016 on the five new urban routes in the capital, being a big success among the passengers. They are equipped with a lower floor and air conditioning, extendible ramps for wheelchairs, information systems and information screens for passengers, as well as interior and exterior cameras.

The objective of the strategic plan for the next several years is to consolidate a reliable and modern public transport system, which is environmentally sound and is equipped with intelligent technologies.

\subsection{Singapore: Master Plan}

The strategic plan for the city of Singapore is conceived for the next 20 years. The main focus points are the development of a more complete public transport network that is more complete and of higher quality. To realize the strategic plan, more than 1700 comments have been received and more than 400 interviews with citizens have been conducted. In addition, there are more than 3,500 comments and incidents received every day.

The areas citizens pointed out as priority are the following:

More Connections to public transportation networks. To shorten the waiting time and reduce the congestion, the amount of buses will be increased, improving their reliability and extending the year-round demand. The public transport system also wants to support a high quality and sustainable lifestyle inside a densely built city. Therefore, low-emission and ecological vehicles are promoted. The barriers against construction noise and other efforts to reduce noise levels will also be important.

Public transport as an attractive way to travel. Like other big cities with traffic restrictions public transport will be the main mode of travel. In Singapore, approximately $63 \%$ of all trips during rush hour are made by public transport. The objective is that $75 \%$ of all trips during rush hour are made by public transport in 2030. To make public transport more attractive, the capacity and reliability of the train and bus service will be improved. The capacity of buses during the rush hour will rise by $110 \%$ with bus lines and additional vehicles. In addition, the bus network will be adjusted, not only to make connections with the railway system easier, but also to reach more places directly.

Improving the bus services: Currently, more than $60 \%$ of trips by public transport are done completely or partially by bus. The buses play a fundamental role as connections to the railway network. Given its important role, immediate measures need to be taken to improve the bus service significantly. There will be more buses to improve the service frequency, reliability, and comfort. Moreover, integrated transport centres, bus centres, priority measures, and real time passenger information will be developed. The fleet will increase by $20 \%$, an equivalent of 800 new buses in the next five years. 550 out of these 800 buses will be financed by the government; the rest will be financed by the public bus operators. Travel information is advancing: travellers can see the timetables of all bus services that leave from the bus interchange. Currently, the arrival times are shown on the display panel at 51 bus stops and 31 are adding information panels this year. Another study was about the viability to give information about the congestion level in buses so travellers can make more informed decisions during their trips. Additionally, a new bus infrastructure will be developed that tackles planning, development, and financing of new bus depots and bus parking lots. 


\subsection{Melbourne (Australia): Strategic Transport Plan}

Melbourne is the biggest city in the state of Victoria, Australia. It was the capital of Australia between 1901 and 1927 until it was moved to Canberra. It is the second biggest city in terms of population after Sydney with 4.1 million inhabitants in its metropolitan area.

The strategic plan of Melbourne establishes the direction, political objectives, and growth plans of the city of Melbourne for 2030. The strategic plan takes into account the significant transport policy changes, the strong growth in public transport use, and cycling mobility, since the transport strategy of 2006.

The community and the stakeholders have participated in the update. This participation included several workshops and briefings for stakeholders, industry, and community. In May 2011, a draft strategy was published with an audience contribution to the statement for the final strategy. This version was finally approved by the Council on 2012. The strategy shares five global objectives:

Coordinating the transport initiatives of the city of Melbourne: plans, programs, research and fifteen-year programs of main projects.

Coordinating the strategic development policy of land use of the city of Melbourne.

Defending the position of Melbourne regarding transport and the policy linked to land use.

Allowing for the alignment between the city of Melbourne and the investment of the state government in transport infrastructure, improvement of services, programs, and research.

Allowing the alignment between the city of Melbourne and other stakeholders, including business people, companies, universities, and neighbours.

Regarding the bus, the weight it carries in the city of Melbourne is reduced as compared to other modes of transport ( $2 \%$ on bus, $10 \%$ on tram, $37 \%$ on train, $5 \%$ on bicycle, and $40 \%$ private vehicle).

The objective of the strategic plan regarding the bus is its development as an efficient mode of transport and a priority for residents, workers, and visitors to the city of Melbourne. The bus routes in the city's central streets will improve by reducing the route time by $30 \%$.

The strategic plan considers an investment in the bus system as a relatively cheap form of improving the transport service. The improvement of existing bus routes or the addition of new routes can be a precursor to future railway and tramway extensions. The main points are:

Installing bus lanes and increasing the frequency of the services.

Improving the bus frequency and the bus system's working speed to avoid being affected by traffic congestion. This could be through bus lanes, traffic sign priority, and safe and efficient stops and bus interchanges.

$\square \quad$ Increasing the bus stops, if necessary eliminating public parking places or undertaking other measures in order to improve the accessibility of the bus stop.

Working with the transport department to enhance the bus interchange performance.

Improving the NightRider bus service, including smaller and more flexible buses.

Reducing Green House Gas emissions and energy costs. The technological innovation of vehicles will continue to provide opportunities to make the buses of Melbourne more efficient in terms of petrol consumption.

$\square \quad$ Introducing a clean fuel bus fleet by 2018 .

\section{Discussion and Conclusions}

This paper has reviewed the literature related to urban bus systems worldwide, looking at its barriers, existing tendencies and measures for improvement, and an overview that is related to the future of transportation related to new technologies. A focus on sustainable mobility by bus in urban environments and recent trends are highlighted. It has been identified that strategies and operational or tactical actions are lacking in the reviewed literature. Therefore, this article showed strategic city 
and bus plans towards sustainability, looking at the way in which strategy was created and developed, how barriers were identified and what strategic measures will be implemented in the near future. In this way, ten cities have been analysed. The most common and essential issues that should be highlighted are:

There is a high participation of the different interest groups, both in the diagnosis and in the action and improvement proposals in most of the analysed cities using different participation methodologies.

There is a big importance in positioning the bus as the main mode of public transport with a significantly increased demand (more than 40 or $50 \%$ in most of cases).

Investments in acquiring a greener fleet (last generation diesel and, mainly, CNG and electric) with an adaptation of the depots as key elements on a short and medium term in all cases. The bus system is the tool for a greater contribution for improving air quality of cities and global climate change (reduction or elimination of emissions and improvement in local health).

$\square \quad$ There are many good practices related with BRT (mainly in North and South America) to improve times, frequencies, and speed, as well as, inclusively, an increase of exclusive or shared bus lanes or bus platforms.

$\square \quad$ Technology and communication are cross-cutting elements that appear constantly in all cases based on the connection with users and non-users (off-board and on-board).

Finally, universal accessibility and synergies with local and regional mobility through other modes of transport (mainly with the underground and where appropriate, on foot and by bicycle) appear at the centre of the strategies towards sustainability.

From a critical point of view, after this review and transversal comparison, an initial maturity level on sustainable mobility by bus in each city should be done, in order to have a better comparison. With this study, general trends and specific approaches can be found, but for a better understanding on each specific case a relativism approach should be developed, analysing each context. From the applied comparative approach, a universal strategic thinking for sustainability is not easy to reach since we are comparing different contexts and maturity levels in the bus system. It may be interesting to develop a public transportation maturity model for its application and to allow a deeper understanding between different cities and strategies according to its development level.

The following Table 2 summarizes the strategic measures found in the analysed cities. It is important to note that it shows the most highlighted measures as strategic and some other measures that may be implemented in the short and medium term. So, this table must be used as a strategic view, not as a specific and tactical application where some issues may lack. In this sense, an increase on the offer to new spaces and lines with specific bus platforms (separated lines or BRT) is almost common in all plans. But, it is also seeking the enhancement of customer experience by different strategies: safety and security, reliability, increase of frequency, real time information, and so on. The renewal of the fleet towards an environmental friendly technology with an increase in the bus service is also a common pattern in most of them. 
Table 2. Summary of measures for bus system improvement.

\begin{tabular}{|c|c|c|c|c|c|c|c|c|c|c|c|}
\hline Areas & Measures for Improvement & New York & Memphis & Montreal & $\begin{array}{l}\text { Santiago } \\
\text { de Chile }\end{array}$ & Bogotá & London & Madrid & Oman & Singapore & Melbourne \\
\hline \multirow{10}{*}{$\begin{array}{l}\text { Infrastructure and } \\
\text { Operations }\end{array}$} & BRT/BHLS & $\mathrm{x}$ & $\mathrm{x}$ & & $\mathrm{x}$ & $\mathrm{x}$ & & & & & \\
\hline & Separated bus lanes & $\mathrm{x}$ & & & & & $\mathrm{x}$ & $\mathrm{x}$ & $\mathrm{x}$ & & $\mathrm{x}$ \\
\hline & Modifying the offer & $\mathrm{x}$ & $\mathrm{x}$ & $\mathrm{x}$ & $\mathrm{x}$ & $\mathrm{x}$ & $\mathrm{x}$ & & & $\mathrm{x}$ & $\mathrm{x}$ \\
\hline & Express and limited stop bus services & $\mathrm{x}$ & & & & & & & & & $\mathrm{x}$ \\
\hline & More frequency & & & $\mathrm{x}$ & & & $\mathrm{x}$ & & & $\mathrm{x}$ & $\mathrm{x}$ \\
\hline & Bus priority measures & $\mathrm{x}$ & & & & & & $\mathrm{x}$ & & $\mathrm{x}$ & \\
\hline & Advanced software for operation management & & & $\mathrm{X}$ & & $\mathrm{x}$ & & & & & \\
\hline & Adequation of facilities and depots & $\mathrm{x}$ & $\mathrm{x}$ & & & & & $\mathrm{x}$ & $\mathrm{x}$ & & \\
\hline & Human resources (training, sensitivity) & & & $x$ & & & & $x$ & & & \\
\hline & Networks connections & & & & & & & & & & \\
\hline \multirow{9}{*}{$\begin{array}{c}\text { Bus Service } \\
\text { Quality-Attractiveness }\end{array}$} & Bus marketing & & & & & & & $\mathrm{x}$ & & & \\
\hline & $\begin{array}{l}\text { Passenger information measures (RTI, Real Time } \\
\text { Information) }\end{array}$ & & & & & $\mathrm{x}$ & & $x$ & $\mathrm{x}$ & $x$ & \\
\hline & Frequency/Regularity & & & $\mathrm{x}$ & & & & & & & $\mathrm{x}$ \\
\hline & Fares & & & & & & & & & $\mathrm{x}$ & \\
\hline & Reliability & $\mathrm{x}$ & & & $\mathrm{x}$ & & $\mathrm{X}$ & & $\mathrm{x}$ & $\mathrm{x}$ & \\
\hline & $\begin{array}{l}\text { Availability of information for connecting to } \\
\text { other public transportation services (MaaS) }\end{array}$ & & & & & & & $\mathrm{x}$ & & & \\
\hline & Easy boarding/Comfort & & & $\mathrm{x}$ & & $\mathrm{x}$ & & & $\mathrm{x}$ & $\mathrm{x}$ & \\
\hline & Non-user perception & & & & & & $\mathrm{x}$ & $\mathrm{x}$ & & & \\
\hline & Customer experience & & & & & & & $\mathrm{x}$ & & & \\
\hline \multirow{6}{*}{ Vehicles (Buses) } & $\begin{array}{c}\text { Major new buses } \\
\text { (CNG, electrical vehicles, hydrogen) } \\
\text { Mini buses }\end{array}$ & $\begin{array}{c}\mathrm{X} \\
(\mathrm{CNG})\end{array}$ & $\mathrm{x}$ & $\begin{array}{c}\mathrm{X} \\
\text { (Electrical) }\end{array}$ & & & $\begin{array}{c}\mathrm{X} \\
\text { (Electrical) }\end{array}$ & $\begin{array}{c}\mathrm{X} \\
(\mathrm{CNG}+\underset{\mathrm{X}}{\mathrm{X} \text { ectrical })} \\
\end{array}$ & $\mathrm{x}$ & $\mathrm{x}$ & $\begin{array}{c}\mathrm{X} \\
(\mathrm{CNG}) \\
\mathrm{X}\end{array}$ \\
\hline & Accessibility for all users & & & & $\mathrm{x}$ & $\mathrm{x}$ & & $\mathrm{x}$ & & & \\
\hline & Hybrid (electric based) & $\mathrm{x}$ & & & & & & & & & \\
\hline & Safety and security & $\mathrm{x}$ & & & $\mathrm{x}$ & & & $\mathrm{x}$ & & & $\mathrm{x}$ \\
\hline & Technical and economical maintenance & $\mathrm{x}$ & $\mathrm{x}$ & & & & & & & & $\mathrm{x}$ \\
\hline & Passenger accounting systems & $\mathrm{x}$ & & & & & $\mathrm{x}$ & $\mathrm{x}$ & & & \\
\hline
\end{tabular}


It seems, therefore, with this short walk around the world using the current and future situation of sustainable mobility strategies, that the urban bus transport, not a flying, shared, or autonomous car, can be the transport of the future. Therefore, due to city capacity, infrastructure costs, and its rigidity, collective bus transportation with priority or exclusive routes, accessibility of stops and stations, frequency and speed improvements, as well as flexibility in a changing environment makes this mode of transport ideal for a desirable air quality in cities. Hence, it seems that the strategy is not so much to invent the future but to improve the present. The transportation of the future will be mainly by bus, following different forecasts in the medium and long-term plans. It remains to be seen how many of the innovations that are being worked on will make us equate the current bus with one of the future: one that will be able to be electric, autonomous, with BRT or bus-lane routes, dynamically connected with users and stops, with technological interactions with urban signage, etc. In fact, many of the strategies have already planned a growth in bus demand by $50 \%$ in the near future, with electric vehicles, and with investment in infrastructure and improvement of the network. In more specific cases, there are attempts to assess the potential of the bus as an autonomous vehicle in pilot projects. Future urban transport will obviously not only be by bus, but a balanced mix between high technology and low technology solutions [25].

It seems that it will be on the bus, where current innovations that are being applied to private vehicles will synergistically integrate, and the means of collective transport will be the only one with the viability and capacity to mobilize the large number of people that flood the cities. Or maybe not, and the strategies of urban bus systems are wrong in their forecasts.

Author Contributions: Á.F.-H.: collaborates doing research and reviewing the paper. G.F.-S.: collaborates doing research, writing the paper, doing the state of the art and being the contact with referees and editor. All authors read and approved the final manuscript.

Funding: This research received no external funding.

Acknowledgments: We would like to thank Eduardo Ubeda and colleagues since they were the academic seed of this paper. Special thanks also to referees that have improved the state of knowledge and the structure of this final document based on their comments.

Conflicts of Interest: The authors declare no conflict of interest.

\section{References}

1. Currie, G.; Rose, J. Growing patronage-challenges and what has been found to work. Res. Transp. Econ. 2008, 22, 5-11. [CrossRef]

2. Silvia Cruz, I.; Katz-Gerro, T. Urban public transport companies and strategies to promote sustainable consumption practices. J. Clean. Prod. 2016, 123, 28-33. [CrossRef]

3. Cascajo, R.; Monzon, A. Assessment of innovative measures implemented in European bus systems using key performance indicators. Public Transp. 2014, 6, 257-282. [CrossRef]

4. Currie, G.; Wallis, I. Effective ways to grow urban bus markets-a synthesis of evidence. J. Transp. Geogr. 2008, 16, 419-429. [CrossRef]

5. Ibarra-Rojas, O.J.; Delgado, F.; Giesen, R.; Muñoz, J.C. Planning, operation, and control of bus transport systems: A literature review. Transp. Res. Part B Methodol. 2015, 77, 38-75. [CrossRef]

6. Diab, E.I.; Badami, M.G.; El-Geneidy, A.M. Bus transit service reliability and improvement strategies: Integrating the perspectives of passengers and transit agencies in North America. Transp. Rev. 2015, 35, 292-328. [CrossRef]

7. Venter, C.; Jennings, G.; Hidalgo, D.; Valderrama, A.D. The equity impacts of bus rapit transit: A review of the evidence and implications for sustainable transport. Int. J. Sustain. Transp. 2017, 12, 140-152. [CrossRef]

8. Macario, R.; Jara-Diaz, S. Growing patronage: Challenges and what has been found to work. Res. Transp. Econ. 2008, 22, 12-15. [CrossRef]

9. Mohamad, J. Urban transport and growth management strategies: A tale of two Southeast Asian cities at the dawn of the new millenium. Malays. J. Soc. Space 2005, 1, 11-22. 
10. Daraio, C.; Diana, M.; Di Costa, F.; Leporelli, C.; Matteucci, G.; Nastasi, A. Efficiency and effectiveness in the urban public transport sector: A critical review with directions for future research. Eur. J. Oper. Res. 2016, 248, 1-20. [CrossRef]

11. Hidalgo, D.; Muñoz, J.C. A review of technological improvements in bus rapid transit (BRT) and buses with high level of service (BHLS). Public Transp. 2014, 6, 185-213. [CrossRef]

12. Nikitas, A.; Karlsson, M. A worldwide state-of-the-art analysis for bus rapid transit: Looking for the success formula. J. Public Transp. 2015, 18, 1-33. [CrossRef]

13. Saleh, W.; Ziolkowski, R. Study on the separated bus lanes effectiveness in city centres: A case study in Edinburgh and Bialystok. World J. Sci. Technol. Sustain. Dev. 2015, 12, 257-268. [CrossRef]

14. Ambarwati, L.; Verhaeghe, R.; van Arem, B.; Pel, A.J. The influence of integrated space-transport development strategies on air pollution in urban areas. Transp. Res. Part D Transp. Environ. 2016, 44, 134-146. [CrossRef]

15. Rajashekara, K.; Wang, Q.; Matsuse, K. Flying cars: Challenges and propulsion strategies. IEEE Electrif. Mag. 2016, 4, 46-57. [CrossRef]

16. Floreano, D.; Wood, R.J. Science, technology and the future of small autonomous drones. Nature 2015, 521, 460-466. [CrossRef] [PubMed]

17. Abdelrahman, A.S.; Sayeed, J.; Youseff, M.Z. Hiperloop transportation system: Analysis, design, control and implementation. IEEE Trans. Ind. Electron. 2018, 65, 7427-7436. [CrossRef]

18. Decker, K.; Chin, J.; Peng, A.; Summers, C.; Nguyen, G.; Oberlander, A.; Sakib, G.; Sharifrazi, N.; Heath, C.; Gray, J.S. Conceptual Feasibility Study of the Hiperloop Vehicle for Next-Generation Transport; AISA Sci Tech 2017; American Institute of Aeronautics and Astronautics: Grapevine, TX, USA, 2017; p. 22.

19. Chowdhury, M.; Dey, K. Intelligent transportation systems-a frointer for breaking boundaries of traditional academic engineering disciplines. IEEE Intell. Transp. Syst. Manag. 2016, 8, 4-8. [CrossRef]

20. Le Vine, S.; Polak, J. Introduction to Special Issue: New directions in shared-mobility research. Transportation 2015, 42, 407-411. [CrossRef]

21. Hensher, D.A. Future bus transport contracts under a mobility as a service (MaaS) regime in the digital age: Are they likely to change? Transp. Res. Part A 2017, 98, 86-96. [CrossRef]

22. Alessandrini, A.; Campagna, A.; Delle Site, P.; Filippi, F.; Persia, L. Automated vehicles and the rethinking of mobility and cities. Transp. Res. Procedia 2015, 5, 145-160. [CrossRef]

23. Davidson, P.; Spinoulas, A. Autonomous vehicles-what could this mean for the future of transport? In Proceedings of the AITPM 2015 National Conference-Modelling Autonomous Vehicles, Brisbane, Australia, 28-31 July 2015.

24. Sparrow, R.; Howards, M. When human beings are like drunk robots: Driverless vehicles, ethics, and the future of transport. Transp. Res. Part C Emerg. Technol. 2017, 80, 206-215. [CrossRef]

25. Nikitas, A.; Kougias, I.; Alyavina, E.; Njoya Tchouamou, E. How can autonomous and connected vehicles, electromobility, BRT, hyperloop, shared use mobility and mobility-as-a-service shape transport futures for the context of smart cities? Urban Sci. 2017, 1, 36. [CrossRef]

26. Wan, D.; Kamga, C.; Liu, J.; Sugiura, A.; Beaton, E.B. Rider perception of a "light" bus rapid transit system-The New York city select bus service. Transp. Policy 2016, 49, 41-55. [CrossRef]

27. Hidalgo, D.; Graftieaux, P. Bus rapid transit systems in Latin America and Asia: Results and difficulties in 11 cities. Transp. Res. Rec. J. Transp. Res. Board 2008, 2072, 77-88. [CrossRef]

28. Corazza, M.V.; Guida, U.; Musso, A.; Tozzi, M. A new generation of buses to support more sustainable urban transport policies: A path towards "greener" awareness among bus stakeholders in Europe. Res. Transp. Econ. 2016, 55, 20-29. [CrossRef]

29. C40 Cities. Clean Bus Declaration. 2015. Available online: http://www.c40.org/networks/low_emission_ vehicles (accessed on 18 November 2018).

30. Debnath, A.K.; Chin, H.C.; Haque, M.M.; Yuen, B. A methodological framework for benchmarking smart transport cities. Cities 2014, 37, 47-56. [CrossRef]

(C) 2018 by the authors. Licensee MDPI, Basel, Switzerland. This article is an open access article distributed under the terms and conditions of the Creative Commons Attribution (CC BY) license (http:// creativecommons.org/licenses/by/4.0/). 